\title{
In vitro activity of gentamicin and amikacin against Salmonella enterica serovar Typhi: a search for a treatment regimen for typhoid fever
}

S. Mandal, ${ }^{1}$ M.D. Mandal ${ }^{1}$ and N.K. Pal ${ }^{1}$

فعَّالية الجينتاميسين والأميكاسين في المختبر ضد السالمونيلة المعوية من النمط المصلي التيفي: بحث عن نظام لمعالجة

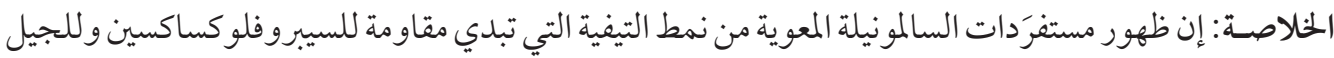

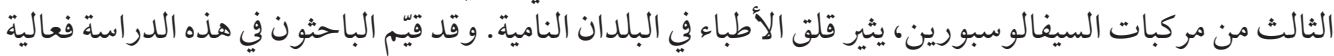

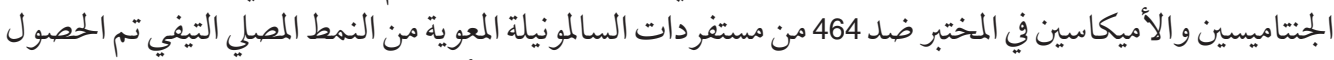

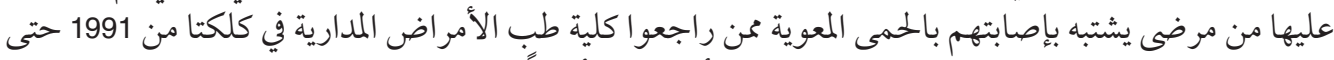

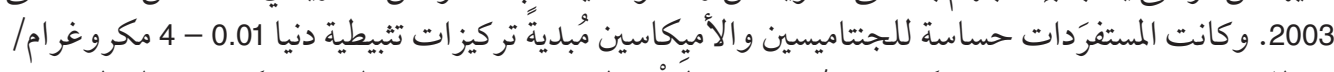

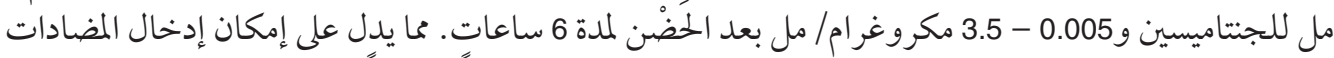

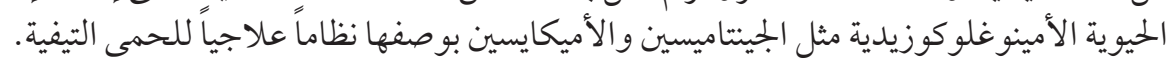

ABSTRACT The emergence of Salmonella enterica serovar Typhi isolates resistant to ciprofloxacin and 3 rd-generation cephalosporins is a concern for physicians in developing countries. This study assessed the in vitro activity of gentamicin and amikacin against $464 \mathrm{~S}$. enterica serovar Typhi isolates obtained from blood of patients clinically suspected of enteric fever who attended the Calcutta School of Tropical Medicine from 1991 to 2003. The isolates were sensitive to gentamicin and amikacin, showing minimum inhibitory concentrations $0.01-4 \mu \mathrm{g} / \mathrm{mL}$ and $0.005-3.5 \mu \mathrm{g} / \mathrm{mL}$ respectively. Both agents showed bactericidal activity at concentrations of $2 \mu \mathrm{g} / \mathrm{mL}$ after incubation for 6 hours. Aminoglycoside antibiotics such as gentamicin and amikacin may thus be introduced as a treatment regimen for typhoid fever.

Activité in vitro de la gentamicine et de l'amikacine contre Salmonella enterica serovar Typhi : recherche d'un schéma thérapeutique pour la fièvre typhoïde

RÉSUMÉ L'apparition d'isolats de Salmonella enterica serovar Typhi montrant une résistance à la ciprofloxacine et aux céphalosporines de 3e génération inquiète les médecins des pays en développement. La présente étude a évalué l'activité in vitro de la gentamicine et de l'amikacine contre 464 isolats de $S$. enterica serovar Typhi obtenus à partir de prélèvements sanguins chez des patients cliniquement suspects de fièvre entérique qui ont consulté à la Calcutta School of Tropical Medicine de 1991 à 2003. Les isolats étaient sensibles à la gentamicine et à l'amikacine et présentaient des concentrations minimales inhibitrices respectivement comprises entre 0,01 et $4 \mu \mathrm{g} / \mathrm{mL}$ et entre 0,005 et $3,5 \mu \mathrm{g} / \mathrm{mL}$. Les deux agents ont montré une activité bactéricide à des concentrations de $2 \mu \mathrm{g} / \mathrm{mL}$ après une incubation de 6 heures. Les aminosides tels que la gentamicine et l'amikacine peuvent donc être utilisés comme schéma thérapeutique pour la fièvre typhoïde.

${ }^{1}$ Department of Bacteriology and Serology, Calcutta School of Tropical Medicine, Kolkata, India (Correspondence to N.K. Pal: samtropmed@rediffmail.com).

Received: 26/09/06; accepted: 07/11/06

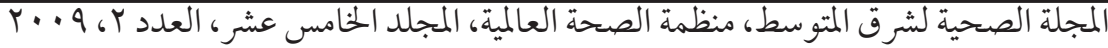




\section{Introduction}

Enteric fever due to infection with Salmonella enterica serovar Typhi is a major health hazard, even with the introduction of newer antimicrobial drugs. In the last decade $S$. enterica serovar Typhi has rapidly developed resistance to antibiotics such as ampicillin, chloramphenicol and cotrimoxazole, and also to ciprofloxacin [1,2]. Multidrug-resistant (MDR) enteric fever continues to be a worldwide health problem $[3,4]$ and the emergence of $S$. enterica serovar Typhi isolates showing resistance to ciprofloxacin and the 3rd-generation cephalosporins is a cause of concern for physicians in developing countries [5-7].

The aminoglycoside antibiotics are not recommended for treating enteric fever due to infection with $S$. enterica serovar Typhi; however, based on the in vitro results, therapy with gentamicin and amikacin has been found to be effective against MDR $S$. enterica serovar Typhi infection. Anand et al. showed that the strains of MDR $S$. enterica serovar Typhi involved in an enteric fever epidemic in Kolkata, India, in 1989 were $100 \%$ sensitive to gentamicin, and there was clinical response for $60 \%$ of patients with gentamicin therapy [4]. Adhikari et al. reported clinical cure of ciprofloxacin-resistant enteric fever with gentamicin [5]. Daga et al. documented the clinical cure of ciprofloxacin-resistant enteric fever using both gentamicin and amikacin [8]. A susceptibility trend for aminoglycosides will help develop guidelines for treatment.

As there is no report on susceptibility to aminoglycosides by $S$. enterica serovar Typhi isolates on a large scale from this part of India, this study was undertaken to assess the in vitro activity of 2 aminoglycosides (gentamicin and amikacin) against blood culture isolates of $S$. enterica serovar Typhi from within and outside Kolkata, India.

\section{Methods}

The $S$. enterica serovar Typhi isolates used in the study were obtained from the blood of all patients clinically suspected of enteric fever who attended the Calcutta School of Tropical Medicine from January 1991 to December 2003.

A total of 464 S. enterica serovar Typhi isolates were tested for susceptibility to gentamicin and amikacin by the agar dilution as well as the disk diffusion method, according to the criteria of the National Committee for Clinical Laboratory Standards (NCCLS) $[9,10]$ using Mueller-Hinton agar medium. The doses of gentamicin and amikacin used to determine the minimum inhibitory concentration (MIC) values were $0.005-5 \mu \mathrm{g} / \mathrm{mL}$ and $0.001-4 \mu \mathrm{g} / \mathrm{mL}$ respectively. For the disk diffusion method the antibiotic doses of both gentamicin and amikacin were $10 \mu \mathrm{g} / \mathrm{disk}$. The details of the methods are described elsewhere [11]. Escherichia coli ATCC 25922 strain was used as the control.

For 1 isolate, bacterial killing studies were carried out to measure changes over time. Overnight growths from a bacterial suspension were diluted to approximately $5 \times 105$ colony forming units $(\mathrm{CFU}) / \mathrm{mL}$ (by colony count method) in fresh MuellerHinton broth (Hi-Media, Mumbai, India) containing antibiotics $(2 \mu \mathrm{g} / \mathrm{mL}$ gentamicin and $2 \mu \mathrm{g} / \mathrm{mL}$ amikacin) or no antibiotic. The samples were removed at $0,3,6$ and $24 \mathrm{~h}$ and were diluted and plated on Mueller-Hinton broth. The agar plates were incubated at $37^{\circ} \mathrm{C}$ for $24 \mathrm{~h}$ and $\mathrm{CFU}$ were counted. A decrease in $3 \log _{10} \mathrm{CFU} / \mathrm{mL}$, with respect to the initial inoculum $\left(5.698 \log _{10} \mathrm{CFU} / \mathrm{mL}\right)$ 
after incubation for $24 \mathrm{~h}$ was considered as the bactericidal activity of the agents [12].

\section{Results}

The $S$. enterica serovar Typhi isolates ( $n$ =464) obtained during 1991-2003 were uniformly susceptible to gentamicin and amikacin with MIC ranging from 0.01-4 $\mu \mathrm{g} / \mathrm{mL}$ and $0.005-3.5 \mu \mathrm{g} / \mathrm{mL}$ respectively (Table 1), as determined by the agar dilution method. In 1991, gentamicin MICs for the isolates were $0.01-0.05 \mu \mathrm{g} / \mathrm{mL}$; the values increased from $0.01 \mu \mathrm{g} / \mathrm{mL}$ (in 1992) to $0.1 \mu \mathrm{g} / \mathrm{mL}$ in 1995 , and $0.5 \mu \mathrm{g} / \mathrm{mL}$ in 1997 . The range of gentamicin MICs for the isolates during 1998-2003 was 0.02-4 $\mu \mathrm{g} / \mathrm{mL}$. Similarly, during the earlier years (199193), the amikacin MIC ranged from 0.005 $\mu \mathrm{g} / \mathrm{mL}$ to $0.1 \mu \mathrm{g} / \mathrm{mL}$. There was an increase in the MIC of amikacin from $0.005 \mu \mathrm{g} / \mathrm{mL}$ (in 1994) to $0.25 \mu \mathrm{g} / \mathrm{mL}$ (in 1997), while the values ranged from $0.025 \mu \mathrm{g} / \mathrm{mL}$ to 3.5 $\mu \mathrm{g} / \mathrm{mL}$ for the isolates during 1998-2003.
All the S. enterica serovar Typhi isolates were susceptible to gentamicin and amikacin using the disk diffusion method.

The results of the time-kill studies are shown in Table 2. Both the antibiotics were inhibitory after $3 \mathrm{~h}$ of incubation. After incubation for $24 \mathrm{~h}$, the bacterial cell count was reduced by $4.488 \log _{10} \mathrm{CFU} / \mathrm{mL}$ for gentamicin $(2 \mu \mathrm{g} / \mathrm{mL})$ and $4.619 \log _{10}$ CFU/mL for amikacin $(2 \mu \mathrm{g} / \mathrm{mL})$, indicating the bactericidal activity of the antibiotics against $S$. enterica serovar Typhi. At concentrations of $2 \mu \mathrm{g} / \mathrm{mL}$, the antibiotic agents also showed bactericidal activity.

\section{Discussion}

The $S$. enterica serovar Typhi is a facultative intracellular pathogen that exists inside the macrophages of typhoid patients. Gentamicin and amikacin are aminoglycoside antibacterial agents that are mainly used for the treatment of extracellular pathogen infections, such as Pseudomonas aerugi-

\begin{tabular}{lccc}
\hline \multicolumn{4}{l}{$\begin{array}{l}\text { Table } \\
\text { aminoglycoside antibiotics gentamicin and amikacin on Salmonella }\end{array}$} \\
$\begin{array}{l}\text { enterica } \\
\text { serovar Typhi isolates }(\boldsymbol{n}=\mathbf{4 6 4})\end{array}$ \\
\hline Year & No. of isolates & MIC $(\boldsymbol{\mu} \mathbf{g} / \mathbf{m L})$ range of antimicrobial agents \\
Gentamicin & Amikacin \\
\hline 1991 & 64 & $0.01-0.05$ & $0.005-0.10$ \\
1992 & 44 & $0.01-0.10$ & $0.005-0.10$ \\
1993 & 31 & $0.01-0.10$ & $0.01-0.10$ \\
1994 & 44 & $0.01-0.10$ & $0.005-0.25$ \\
1995 & 38 & $0.01-0.10$ & $0.01-0.25$ \\
1996 & 30 & $0.01-0.20$ & $0.01-0.25$ \\
1997 & 26 & $0.01-0.50$ & $0.01-0.25$ \\
1998 & 32 & $0.02-0.75$ & $0.025-0.50$ \\
1999 & 42 & $0.02-2.00$ & $0.05-20$ \\
2000 & 28 & $0.05-1.25$ & $0.10-20$ \\
2001 & 42 & $0.20-2.00$ & $0.10-20$ \\
2002 & 20 & $0.50-4.00$ & $1.25-3.5$ \\
2003 & 23 & $0.75-4.00$ & $1.50-3.5$ \\
\hline
\end{tabular}


Table 2 Viability of Salmonella enterica serovar Typhi after 0-24 hours incubation in the presence of the aminoglycoside antibiotics gentamicin and amikacin $(2 \mu \mathrm{g} / \mathrm{mL})$

\begin{tabular}{lcccc}
\hline Agent & \multicolumn{4}{c}{ Log $_{10}$ colony forming units/mL } \\
& 0 hours & 3 hours & 6 hours & 24 hours \\
\hline Gentamicin & 5.698 & 4.312 & 2.583 & 1.110 \\
Amikacin & 5.698 & 4.120 & 2.310 & 1.079 \\
No antibiotic & 5.698 & 5.980 & 6.440 & 7.842 \\
\hline
\end{tabular}

nos $a$ and $E$. coli infections, and thus are not commonly used for the treatment of typhoid fever. Because aminoglycosides have difficulty penetrating tissue or cells they are less likely to be effective for facultative intracellular pathogens such as S. enterica serovar Typhi. However, many authors include aminoglycoside antibiotics such as gentamicin and amikacin in susceptibility testing to assess the in vitro efficacy of these antibiotics in order to create a treatment regimen for MDR typhoid fever when it is urgently required $[4,5,8]$. Moreover, there are reports of treatment failures in typhoid fever with ciprofloxacin as well as the 3rd-generation cephalosporins $[5,6]$. In such circumstances, there is a need to find a cost-effective treatment regimen for typhoid fever.

For Enterobacteriaceae, the NCCLS MIC cut-offs for gentamicin susceptibility and resistance are $\leq 4 \mu \mathrm{g} / \mathrm{mL}$ and $\geq 8 \mu \mathrm{g} / \mathrm{mL}$ respectively, and that of amikacin susceptibility and resistance are $\leq 16 \mu \mathrm{g} / \mathrm{mL}$ and $\geq 32 \mu \mathrm{g} / \mathrm{mL}$ respectively. Thus, although the S. enterica serovar Typhi isolates in our study showed annual increases in the MIC of gentamicin and amikacin, these values are well below the resistance level. Similar to other studies $[13,14]$, the isolates in our region were also found to be susceptible to gentamicin and amikacin by disk diffusion. These other studies did not report the MIC of the agents. However, in our study, the MICs of gentamicin and amikacin were $0.01-4 \mu \mathrm{g} / \mathrm{mL}$ and $0.005-3.5 \mu \mathrm{g} / \mathrm{mL}$ respectively, which is even below the susceptibility breakpoints as stated by the NCCLS. In addition, in the current study, we found that both gentamicin and amikacin showed bactericidal effect on the tested $S$. enterica serovar Typhi isolates at very low concentrations $(2 \mu \mathrm{g} / \mathrm{mL})$ after $6 \mathrm{~h}$ incubation.

Our data suggest that a therapeutic trial with gentamicin and/or amikacin might establish a cost-effective therapy for MDR typhoid fever in India and other developing countries, thus keeping at bay, at least during emergencies, the need for costly antimicrobial agents of the newer generation.

\section{References}

1. Mandal S, Mandal MD, Pal NK. Antimicrobial resistance pattern of Salmonella typhi isolates in Kolkata, India during 1991-2001: a retrospective study. Japanese journal of infectious diseases, 2002, 55:58-9.

2. Pal NK, Mandal S, Mandal MD. Scattergram analysis to explore the emerging problem related to in vitro susceptibility test for Salmonella enterica serovar Typhi to ciprofloxacin. International journal of antimicrobial agents, 2004, 24:297-99.

3. Threlfall EJ et al. Drug-resistant enteric fever in the UK. Lancet, 2006, 367:1576.

4. Anand $\mathrm{AC}$ et al. Epidemic multiresistant enteric fever in eastern India. Lancet, 1990, 335:352. 
5. Adhikari PMR, Baliga S. Ciprofloxacinresistant typhoid with incomplete response to cefotaxime. Journal of the Association of Physicians of India, 2002, 50:428-9.

6. Saha SK et al. A highly ceftriaxoneresistant Salmonella typhi in Bangladesh. Pediatric infectious disease journal, 1999, 18:387.

7. Chandel DS, Chaudhry R. Enteric fever treatment failures: a global concern. Emerging infectious diseases, 2001, 7(4):762-3.

8. Daga MK, Sarin K, Sarkar R. A study of culture positive multidrug resistant enteric fever-changing pattern and emerging resistance to ciprofloxacin. Journal of the Association of Physicians of India, 1994, 42:599-600.

9. Approved standard M7-A4. Methods for dilution antimicrobial susceptibility test for bacteria that grow aerobically, 4th ed. Wayne, Pennsylvania, National Committee for Clinical Laboratory Standards, 1997.

10. Approved standard M2-A6. Performance standards for antimicrobial disk suscepti- bility tests, 6th ed. Wayne, Pennsylvania, National Committee for Clinical Laboratory Standards, 1997.

11. Mandal S, Mandal MD, Pal NK. Reduced minimum inhibitory concentration of chloramphenicol for Salmonella enterica serovar Typhi. Indian journal of medical science, 2004, 58:16-23.

12. Leclercq $R$ et al. Effects of combinations of beta-lactams, daptomycin, gentamicin, and glycopeptides against glycopeptide-resistant enterococci. Antimicrobial agents and chemotherapy, 1991, 35:92-8.

13. Das U, Bhattacharya SS. Antibiogram, phage typing and biotyping of Salmonella typhi and Salmonella paratyphi A from Rourkela, Orissa. Indian journal of medical research, 2006, 124:109-11.

14. Chande $C$ et al. Change in antimicrobial resistance pattern of Salmonella typhi in central India. Indian journal of medical research, 2002, 115:248-50. 